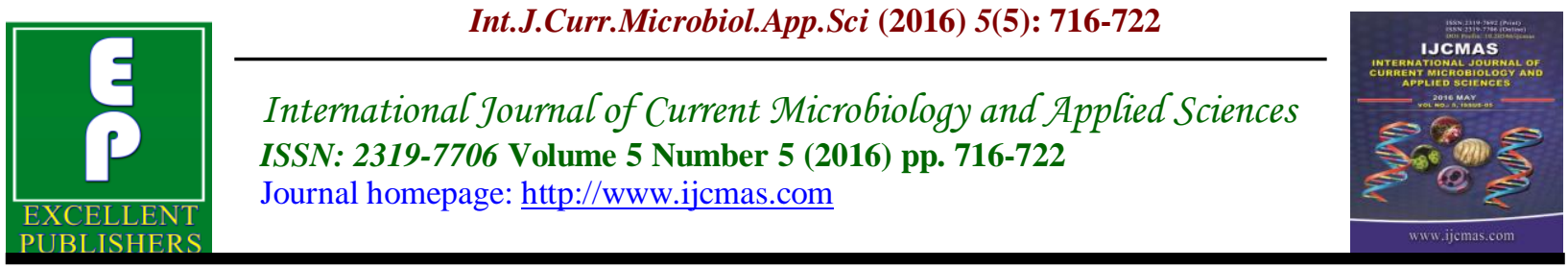

Original Research Article

http://dx.doi.org/10.20546/ijcmas.2016.505.072

\title{
The Prevalence of Cytomegalovirus among Eligible Blood Donors in Keffi, Nigeria
}

\author{
G.R.I. Pennap*, M.E. Joseph and V. B. Oti \\ Microbiology Unit, Nasarawa State University, Keffi, Nigeria \\ *Corresponding author
}

Keywords

Cytomegalovirus, seroprevalence, blood donors, $\operatorname{IgG}$

\section{Article Info}

Accepted:

20 April 2016

Available Online:

10 May 2016

\section{A B S T R A C T}

Cytomegalovirus also called human herpesvirus type 5 (HHV 5) is known to be a significant cause of morbidity and mortality following blood transfusion. In immunocompetent individuals primary CMV infection is usually asymptomatic, the immunosuppressed population for which CMV seronegative blood products are required is increasing due to advances in medical care especially to premature infants, AIDS patients, increasing use of transplantation procedures and immunosuppressed cancer therapies. The aim of this study was to determine the prevalence of cytomegalovirus infection among eligible blood donors in Keffi, Nigeria. Blood samples were collected from 208 consenting participants in the Heamatology Unit of Federal Medical Centre, Keffi. The sera were evaluated for CMV IgG antibody using an ELIS A kit (Cortez Diagnostic, Inc. USA). The overall prevalence for CMV IgG was 74\%. The prevalence of CMV IgG antibody based on sex was $73.9 \%$ in males and $74.2 \%$ in the females. There was no statistically significant association between gender and CMV IgG prevalence ( $\mathrm{p}>0.05$ ). Seroprevalence was found to increase with age from 52.5\% among those aged $<20$ years to $81.8 \%$ among those aged $30-39$ years. Neither occupation nor history of blood transfusion was significantly associated with CMV IgG prevalence among the participants. Of those that have had a blood transfusion $70.6 \%$ were positive to the virus while among those that have never had a transfusion the prevalence of the virus was $74.3 \%$. This study reported a high CMV infection prevalence in this study area. This therefore underscores the need to include CMV screening before blood transfusion and the importance of using strategies such as leukoreduction before any transfusion in this area. Also the medical records of seronegative eligible donors should be kept for emergency contact when patients who are at high risk of developing severe CMV infection are in dire need of transfusion. Proactive strategies of educating people on prevention and control measures should be put in place.

\section{Introduction}

Cytomegalovirus (CMV), a member of the human herpes family of viruses, transmissible through blood transfusions, is an important cause of concern worldwide (Shaiegan et al., 2015). It is a ubiquitous organism found universally in all geographic 
locations. However, CMV is more common in developing countries and in people belonging to lower socio-economic status (Ojide et al., 2012; Arun et al., 2012). The seroprevalence of CMV is $80-100 \%$ in Africa and Latin America (Souza et al., 2010). Like most other herpes viruses, CMV remains latent in the host after primary infection and persists for life in the organism. Latent CMV is associated with white blood cells which aids its transmissionby transfusion of cellular blood components( Matos et al., 2010). Nevertheless, these viruses can be reactivated in immunosuppressed individuals and can be an important cause of morbidity and mortality. CMV can be transmitted by blood transfusion, transplacental route or by transplantation of hematopoietic stem cells and solid organs from infected donors (Zeimann and Hennig, 2014). Most studies suggest that $13-38 \%$ of immunocompromised patients will contract CMV from transfusion of unscreened and unfiltered cellular blood components (Souza et al., 2010; Arun et al., 2012; Oladipo et al., 2014). Therefore, the most effective way to minimize the risk of CMV transmission in high risk recipients would be to administer CMV free blood products. The immunosuppressed population for whom CMV free blood products are requested is increasing due to advances in medical care (Lopo et al., 2011).

The diagnosis of CMV infection can be relied on different techniques including: electron microscopic detection of typical CMV virion, histologic or cytologic detection of typical CMV cytopathology, isolation of virus, detection of CMV antigen in blood and tissues, detection of CMV genome in tissues, DNA amplification, and serology techniques based on CMV antibodies detection. The diagnosis of CMV infection in immunocompromised patients can be difficult as it requires virus detection and determination of CMV as the cause of the disease (Shaiegan et al., 2015). Several other tests are available including: DNA probe techniques, polymerase chain reaction (PCR), and immunofluorescence technique for detection of CMV early antigen in circulating leucocytes (Furui et al., 2013). One of the most common available serologic tests to detect CMV IgG and CMV IgM antibodies is based on enzyme-linked immunosorbent assay (ELISA). IgG positive result is indicative of a person infected by CMV during his or her life (Furui et al., 2013). CMV IgM presence could be interpreted as new infection, acute infection or re-activation of CMV. It has been reported that CMV infection rate increases with blood donor age. Transfusion transmissible infections (TTIs) are a very serious complication of blood transfusion. These infections continue to pose a great challenge to transfusion medicine, especially in Africa, due to a high transfusion demand (Zeimann and Hennig, 2014). This study was therefore carried out to determine the seroprevalence of Cytomegalovirus among eligible blood donors in Keffi, Nigeria.

\section{Materials and Methods}

\section{Study Area and Population}

The area of study for this research was Keffi. It is approximately $68 \mathrm{Km}$ from Abuja, the Federal Capital Territory and $128 \mathrm{Km}$ from Lafia, the capital of Nasarawa State. Keffi is located between latitude 8 $5^{\prime} \mathrm{N}$ of the equator and longitude $78^{\prime} \mathrm{E}$ and situated on an altitude of $850 \mathrm{~m}$ above sea level (Akwa et al., 2007).

The study population was made up of 208 consented eligible blood donors randomly selected from both sexes. Sociodemographic information of the participants 
was obtained through oral interview. Such information includes; age, sex, occupation, history of blood transfusion.

\section{Eligible Blood Donors}

Blood was collected only from those that fulfilled the criteria of being eligible donors. For the purpose of this study, such a participant must have been;

$\geq 50 \mathrm{~kg}$ in weight

Physically healthy

Aged $\geq 18$ years

\section{Sample Collection}

After obtaining a verbal informed consent from each participant, $5 \mathrm{ml}$ blood sample was collected by vein puncture into a sterile vacuum plain bottle, allowed to clot for 30 minutes and centrifuged at 3000rpm for 5 minutes. Each resultant serum was harvested into a sterile serum bottle, labeled and stored at $-200 \mathrm{C}$ until ready for ELISA test.

\section{Test Procedure}

The sera were analysed for CMV specific IgG using ELISA kits (Cortez Diagnostic, Inc. USA) according to the manufacturer's instruction.

The CMV antigen coated strips was placed into the holder. A 1: 40 dilution was prepared for each test sample; negative control, positive control and calibrators by adding $5 \mu 1$ of each of these to $200 \mu 1$ of sample diluents. One hundred $\mu 1$ of diluted calibrator, controls (positive and negative) and serum was dispensed into appropriate wells. For the reagent blank, 100 $\mu$ l sample diluentswas dispensed in $1 \mathrm{~A}$ well position of the micro titer plate. The holder was tapped to remove air bubbles from the liquid contact of the wells and mixed by slight agitation. The plate was incubated for 30 minutes at room temperature. The liquid was then removed from all the wells and the plate washed three times with washing buffer. One hundred $\mu \mathrm{l}$ enzyme conjugate was dispensed into each well and further incubated for 30 minutes at room temperature. The enzyme conjugate was removed from wells, the plate was washed three times with washing buffer and $100 \mu 1$ TMB chromogenic substrate was dispensed to each well and the plate incubated for 30 minutes at room temperature. After the incubation period, $100 \mu \mathrm{l}$ of stop solution was added to stop further reaction. Precaution was taken to ensure that there was no air bubble in each well before taking the readings. Optical density (O.D) was read at $450 \mathrm{~nm}$ with a microwell ELISA reader. (BIO-RAD PR2100). Results were interpreted according to the manufacturers' recommendation

\section{Ethical Approval}

Approval for this study was obtained from the Ethical Review Commmittee on Human Research, Federal Medical Centre, Keffi, Nigeria.

\section{Statistical Analysis}

The data obtained were subjected to descriptive statistical analysis using SPSS version 17.0. $\mathrm{C}$ hi-square was used to determine associations and values obtained were considered statistically significant at $\mathrm{p} \leq 0.05$.

\section{Results and Discussion}

Two hundred and eight voluntary blood donors were recruited into this study. Of these, males were $55.3 \%$ while females were 44.7\%. CMV IgGseropositivity among male donors was $73.9 \%$ and $74.2 \%$ among female 
donors. There was no statistically significant difference in the prevalence of the viral infection between the sexes.

Similarly, there was no statistically significant difference in the viral infection prevalence in the different age groups. It ranged from $52.2 \%$ among those aged less than 20 years to $100 \%$ among those aged above 50 years.

There was also no correlation observed between the viral prevalence of infection and either history of blood transfusion or occupation. The $74.0 \%$ CMV-IgG prevalence among eligible blood donors in this study is relatively high. This suggests that many people in the study area have been exposed to the virus, thus the virus can be said to be endemic in Keffi, Nigeria. It also means that there are just about $26 \%$ of eligible blood donors that can comfortably donate blood (with respect to safety of CMV infection) to at risk patients in this environment. The seropositive rate reported in this study is lower than prevalence rates observed in previous studies carried out in other parts of Nigeria. It was $92 \%$ in Jos (Alao et al., 2008), 95.8\% in Benin (Ojide et al., 2012), and 96\% in Lagos (Akinbami et al., 2009) prevalence.

Lower rates were observed in Ogbomoso $25.8 \%$ (Oladipo et al., 2014). Several studies on the prevalence of CMV IgG antibody in different parts of the world have also shown different rates. For example, Ghana 93.2\% (Adjei et al., 2008), Iran $94.82 \%$ and $92 \%$ (Arun et al., 2012; Shaiegan et al., 2015), Turkey $97.2 \%$ (Mutlu et al., 2008) and Brazil 96.4\% (Souza et al., 2010) These differences might be as a result of different screening methods, environmental and climatic factors and socioeconomic status of the study populations. The prevalence of CMV-IgG antibody in this study was shown to vary with age. It ranged from 52.2\% among those aged $<20$ years to $100 \%$ among those aged $\geq$ 50 years. This result is in consonance with the reports from Benin (Ojide et al., 2012) which recorded $100 \%$ seropositivity among those aged $\geq 50$ years but in contrast to reports from Ogbomoso (Oladipo et al., 2014) and from Chennai (Arun et al., 2012) which recorded a higher prevalence in lower age groups. The $100 \%$ prevalence recorded in this group might be as a result of the paucity of samples screened in that age bracket. In the study area, it is very uncommon to find people of this age group donating blood so it was not easy to get many samples from this age group. There was no statistical association between the seropositivity of CMV-IgG antibody and the age group of participants ( $p>0.05)$ but infection was more common among the youth aged 20 - 39 years. A similar observation was reported from Lahore, Pakistan (Rizvi et al., 2015). In their contribution, Hecker et al., (2012) had posited that seroconversion is a lifelong event and is associated with age.

A history of blood transfusion was also not found to be associated with seropositivity for the viral infection among eligible blood donors ( $p>0.05)$ in the study. This may imply that previous blood transfusion is not the only risk factor for CMV infection. This outcome is in consonance with the outcome of other researchers (Akinbami et al., 2009; Oladipo et al., 2014). The possible explanation is that there are various routes through which CMV is transmitted including intrauterine, breastfeeding, sexual contact and spread from children (Shaiegan et al., 2015).

In this study there was no statistically significant association between the viral IgG antibody prevalence and occupation ( $\mathrm{p}>$ 0.05), implying that occupation has no relationship with CMV infection. This report 
is in agreement with the work of Oladipo et al., (2014) which also recorded that occupation is not related with the viral infection.

Table.1 Seroprevalence of Cytomegalovirus with respect to Risk Factors among Eligible Blood Donors in Keffi, Nigeria

$\begin{array}{llll}\begin{array}{l}\text { Risk Factors } \\ \text { Gender }\end{array} & \text { No. Tested } & \text { No. Positive (\%) } & \text { p value } \\ \text { Male } & 115 & 85(73.9) & >0.05 \\ \text { Female } & 93 & 69(74.2) & \\ \begin{array}{l}\text { Age (years) } \\ <20\end{array} & 23 & 12(52.2) & \\ 20-29 & 141 & 107(75.9) & >0.05 \\ 30-39 & 33 & 27(81.8) & \\ 40-49 & 8 & 5962.5) & >0.05 \\ \geq 50 & 3 & 3(100) & \\ \text { History of Blood } & & & \\ \text { Transfusion } & & 12(70.6) & \\ \text { Yes } & 17 & 142(74.3) & \\ \text { No } & 191 & & \\ \text { Occupation } & & 23(76.7) & \\ \text { Civil servants } & 30 & 114(74.0) & \\ \text { Students } & 154 & 17(70.8) & \\ \text { Artisans } & 24 & & \end{array}$

There was no association between gender and CMV infection in this study ( $>$ > 0.05). The seroprevalence was higher in females $(74.2 \%)$ than their male $(73.9 \%)$ counterparts. This is similar with the report of Oladipo et al., (2014) who recorded higher prevalence in females. However it is in contrast with the work of Arun et al., (2012) where the seroprevalence rate was higher in males $(76.03 \%)$ than females (23.97\%). It has been reported that infected infants and children especially those under 30 months old actively excrete the virus in their saliva and urine and so serve as the common source of infection for adults (Matos et al., 2010). In the study area, children are known to be carried by both male and female adults. So this might have been the reason for the similarity in CMV infection prevalence among males and females. Some researchers have also reported that personal close contact rather than poor hygiene was more important for the transmission of the virus (Fowotade and Nwadike, 2012; Sukruili et al., 2012; Furui et al., 2013; Shaiegan et al., 2015).

In conclusion, a high seroprevalence of CMV IgG antibody (74\%) was reported in this study among eligible blood donors although none of the studied risk factor was significantly associated with the viral infection prevalence. Despite the high prevalence, the routine screening of blood donors for CMV infection in such a resource limited environment might not be feasible. However, the $26 \%$ seronegative donors could be a source of the needed blood for immunosuppressed patients and this can be achieved by keeping an inventory of CMV seronegative blood in the blood bank. Alternatively, leukoreduction filtration could be adapted to minimize transmission. 


\section{References}

Adjei, A. A., Armah, H. B. and NarterOlaga, E. G. (2008). Seroprevalence of Cytomegalovirus among some voluntary blood donors at 37 Military Hospital Accra, Ghana. Ghana Medical Journal, 40 (3): 99-104.

Akinbami, A. A., Akanmu, A. S., Adeyemo, T. A., Wright, K. O., Dada, M. O. and Dosunmu, A. O. (2009). Cytomegalovirus antibodies among healthy blood donors at Lagos University Teaching Hospital.South African Medical Journal, 99 (7): 528530.

Akwa, V. L., Binbol, N. L., Samaila, K. L. and Marcus, N. D. (2007). Geographical perspective of Nasarawa State. Onairi printing and publishing company limited Keffi, Nigeria. Pp 3-12.

Alao, O. O., Joseph, D. E. and Mamman, A. (2008). The seroprevalence of Cytomegalovirus antibodies among prospective blood donors in Jos. Nigerian Journal of Medical, 17: 198200.

Arun, R., Subash, S., Joshua, D. J. and Arumugam, P. (2012).Seroprevalence of human Cytomegalovirus among voluntary blood donors in Chennai. International Journal of Medical Health Sciences, 1 (4): 21-26.

Furui, Y., Satake, M., Hoshi, Y., Uchida, S., Suzuki, K. and Tadokoro, K. (2013). Cytomegalovirus (CMV) seroprevalence in Japanese blood donors and high detection frequency of CMV DNA in elderly donors. Transfusion, 53: 2190-2197.

Fowotade, A. and Nwadike, V. U. (2012). Cytomegalovirus in immunosuppressed patients: a silent and potential killer. African Journal of
Clinical and Experimental Microbiology, 13 (1): 35-40.

Hecker, M., Qui, D., Marquart, K. and Hackstein, H. (2012).Continuous CMV seroconversion in a large group of healthy blood donors. Vox Sanguinis. 86 (1): $41-44$

Lopo, S., Vinagre, E., Palminha, P., Paixao, M. T., Nogueira, P. and Freitas, M. G. (2011). Seroprevalenceto cytomegalovirus in the Portuguese population 2002-2003. Euro survivelance, 16: 1-6.

Matos, S. B., Meyor, R. and Lima, F. W. M. (2010). Seroprevalence of CMV infection among healthy blood donor in Bahia, Brazil. Review of Brazil Hematology Hemoter, 32 (1): 45-49.

Mutlu, B., Gunlemez, A., Turker, G., Gokalp, A. S. and Willke, A. (2008). Is serologic screening necessary in the donor bloods for Cytomegalovirus seronegative blood transfusion to risk patients? Mikrobiyol Bulletin, 42 (2): 337-341.

Ojide, C. K., Ophori, E. A., Eghafona, N. O. and Omoti, C. (2012). Seroprevalence of Cytomegalovirus (CMV) amongst voluntary blood donors in University of Benin Teaching Hospital (UBTH), Edo State, Nigeria. British Journal of Medicine and Medical Research, 2 (1): 15-20.

Oladipo, E. K., Akinpelu, O. O., Oladipo, A. A. and Edowhorhu, G. (2014). Seroprevalence of Cytomegalovirus (CMV) among blood donors of Bowen University Teaching Hospital Ogbomoso. American Journal of Medical and Biological Research, 2 (3): 72-75.

Rizvi, C.B., Raza, M., Siddiqu, M.F. and Alan, R. (2015). Seroprevalence of human cytomegalovirus among blood donors in Lahore, Pakistan. Advance Life Science. 2(4): 171 - 175. 
Shaiegan, M., Rasouli, M., Zadsar, M. and Zolfaghari, S. (2015). Meta-analysis of Cytomegalovirus seroprevalence in volunteer blood donors and healthy subjects in Iran from 1992 to 2013.Iran Journal of Basic Medical Sciences, 18 (7): 627-634.

Souza, M. A., Passos, A. M., Treitinger, A. and Spada, C. (2010). Seroprevalence of Cytomegalovirus antibodies in blood donors in Southern Brazil.Rev. Soc. Bras. Med. Trop, 43: 359-361.
Sukrulia, G.R., Rhadika, C.D. and Anil, K.B. Seroprevalence of transfusiontransmissible infection among voluntary blood donors at KIMS blood bank. Journal of Medical and Science Research. 2014, 2 (3): 137 139.

Ziemann, M. and Hennig, H. (2014). Prevention of transfusion-transmitted Cytomegalovirus infections: which is the optimal strategy? Transfus Med Hemother, 41: 40-44.

\section{How to cite this article:}

Pennap, G.R.I., M.E. Joseph and Oti, V. B. 2016. The Prevalence of Cytomegalovirus among Eligible Blood Donors in Keffi, Nigeria. Int.J.Curr.Microbiol.App.Sci. 5(5): 716-722. doi: http://dx.doi.org/10.20546/ijcmas.2016.505.072 